Article

\title{
Voluntary Certification of Agricultural Products in Competitive Markets: The Consideration of Boundedly Rational Consumers
}

\author{
Xujin $\mathrm{Pu}^{*}$ and Huanzhen Zhang \\ Business School, Jiangnan University, 1800 Lihu Avenue, Wuxi 214122, China; harles_zhz@163.com \\ * Correspondence: puyiwei@ustc.edu; Tel.: +86-510-8519-7970; Fax: +86-510-8532-9087 \\ Academic Editor: Giuseppe Ioppolo \\ Received: 1 June 2016; Accepted: 13 September 2016; Published: 20 September 2016
}

\begin{abstract}
Market competition creates strategic incentives for firms to communicate private information about their own product quality through certification. Although voluntary certification has recently gained importance in the agricultural industry, information asymmetry is not always completely addressed. This study analyzes how the relative proportion of boundedly rational consumers in the market influences the effectiveness of voluntary certification mechanisms by using a duopoly game model of high- and low-quality firms. The presented results show that a change in the proportion of boundedly rational consumers leads to different certification behaviors and a different market equilibrium. We also find that the existence of boundedly rational consumers is an important factor in the failure of voluntary certification. Indeed, when the relative proportion of such consumers is very high, voluntary certification is ineffective at improving market efficiency.
\end{abstract}

Keywords: voluntary certification; agricultural product market; bounded rationality

\section{Introduction}

Nelson [1,2] and Darbi and Karni [3] develop a useful categorization among search, experience and credence attributes. Search attributes are those for which consumers can assess products' quality or qualities before purchasing them. Typical examples are external physical attributes, such as color, size, polish and style, etc. Experience attributes are those for which consumers are not able to assess the products' qualities until they have purchased and consumed them. For example, attributes of taste, system functionality, performance and productivity can only be evaluated based on consumers' trials and past experience. Therefore, the products' experience aspect of quality can be estimated after the consumers have used the product. Finally, credence attributes are the invisible or perceivable aspect of products' quality, including usage of pesticides, environmental contamination, organic fertilizer, and so on. Thus, consumers' cannot assess the credence aspect of quality in the whole purchasing-consuming stage of the products.

When buying an agricultural product, consumers usually lack the expertise to fully perceive the credence attributes of the product quality. Therefore, the agricultural product markets are usually inefficient (termed "markets for lemons" by Akerlof [4]). In the agri-food sector, however, a strategic seller is motivated to disclose some favorable information by implementing independent third-party certification, which is helpful to let consumers know the agri-products better and enhance their willingness to purchase.

In the agricultural industry, voluntary certification is widely used globally because it can improve market efficiency by translating credible attributes into understandable quality signals for consumers. For instance, the U.S. Department of Agriculture (USDA) has historically used voluntary programs such as the Conservation Reserve Program and, more recently, the Environmental Quality 
Incentives Program to induce farmers to withdraw environmentally damaging land from production. Similarly, USDA and the European Union allow organic products meeting their labeling criteria to be branded as such, while the voluntary fresh produce audit verification program developed by the US Food and Drug Administration and USDA certifies firms implementing good agricultural practices. AB (agriculture biologique), LR (label rouge), CCP (appellation d'Origine protégée), and AOC (appellation d'Origine controlee), among other official certifications, are mentioned in the WTO/TRIPS (World Trade Organization/Trade-Related Aspects of Intellectual Property Rights) Agreement and widely recognized by consumers in France.

However, market efficiency resulting from information asymmetry is not fully eliminated by voluntary certification. For instance, Anders et al. [5] find that competition among certification organizations affects the objectivity of the certification process and thereby reduces its effectiveness, particularly because of the increasing number of such organizations and reduction in market concentration. Berghoef and Dodds [6] also indicate that some wine industry members express concerns about the legitimacy of eco-labeling, fearing that if the label is not reputable it could negatively affect the reputations of those involved.

In addition, there exists an issue of mislabeling because of information asymmetry. An opportunistic seller, in particular, may present low-quality products to consumers in the name of high-quality products to obtain additional revenue. For example, the Tageszeitung newspaper reported that "Italian authorities said they had busted a scheme in which more than 700,000 tonnes of non-organic food was sold as organic and sold at the higher prices commanded by such products" [7]. In southern European (Spanish and Greek) market chains, the DNA analysis of commercialized hake products has demonstrated more than $30 \%$ mislabeling, on the basis of species substitution, especially for tails and fillets. In particular, African species were mislabeled as American and European species. Garcia-Vazquez et al. [8] suggest that this is a case of deliberate mislabeling to seek higher profits, because the real market prices of European and American hake products are higher than those of African ones in the Spanish market.

In this study, we analyze a duopoly in which two firms engage in price competition by offering agricultural products that differ only in terms of quality (high or low). In addition, we incorporate market realities by segmenting consumers into two groups. Completely rational consumers (CR consumers hereafter) are knowledgeable about all the quality attributes of the products, whereas boundedly rational consumers (BR consumers hereafter) cannot identify the true product quality for two reasons: (i) they believe in the credibility of the production process or (ii) they believe in the efficiency and objectivity of the certification process.

Based on the analysis presented herein, we find that the proportion of BR consumers influences the effectiveness of voluntary certification mechanisms. A lower proportion of BR consumers compared with CR consumers leads to the pooling equilibrium, namely that neither firm opts for certification. An equal proportion of BR and CR consumers leads to the separating equilibrium, namely a low-quality firm does not opt for certification but a high-quality one does. Finally, a higher proportion of BR consumers leads to the pooling equilibrium, namely that both firms opt for certification.

The remainder of the paper is organized as follows. In the next section, we review the related literature. Section 3 presents the model. In Section 4, we compare the firms' market shares, sales prices, and profits in different settings. Section 5 presents a numerical simulation that analyzes how voluntary certification affects a duopoly market. In Section 6, we conclude with a summary of managerial findings.

\section{Related Literatures}

Researchers of this topic have shown that certification is important for solving the failures of the agriculture market. Dranove and Jin [9] find that third-party disclosure helps consumers make better choices and encourages sellers to improve quality. Ortega et al. [10] show that many consumers believe certification reflects product quality better than brand awareness and point out 
that the third-party certification system by non-governmental organizations plays a positive role in consumer decision-making.

The consensus of behavioral studies is that decision-makers are not CR; instead, they usually make decisions when they are ill-informed (i.e., they are BR; see Simon [11]; Rubinstein [12]; Loch and Wu [13]; and Ariely [14]). Facing a complex market environment, deviations in consumers' decision-making caused by bounded rationality have a considerable influence on market activities. Sarafidis [15] shows that the existence of naïve time-inconsistent consumers reduces not only a monopolist's profits, but also the utility of most other consumers. Chen et al. [16] find that the more BR consumers there are, the higher the prices of low-quality firms will be. Buehler and Schuett [17] compare certification to a minimum quality standard policy in a duopoly where firms incur quality-dependent fixed costs and only a proportion of consumers observe the actual quality of the offered goods. Compared with the unregulated outcome, both profits and social welfare would increase if firms could commit to producing higher-quality products. Shulman and Geng [18] use an analytical model to examine the consequences of add-on pricing when firms are both horizontally and vertically differentiated and there is a segment of BR consumers. When quality asymmetry is on base goods only and with BR consumers, add-on pricing can diminish profit for a qualitatively superior firm and increase profit for an inferior firm compared with when add-on pricing is prohibited or infeasible.

By assuming perfect commitment and treating the seller's quality as exogenously determined, Lizzeri [19] studies the profit-maximizing policies of monopolistic and oligopolistic certifiers. Based on a similar framework, Albano and Lizzeri [20] endogenize the seller's quality choice. Strausz [21] and Mathis et al. [22] focus on the incentives of certifiers to rate the seller's quality honestly.

The foregoing research findings confirm that the influence of BR consumers on the certification of agricultural products has important theoretical and practical significance. However, research in this field is still in its infancy. Similar to Buehler and Schuett [17], we also consider that consumers have different information about quality. However, to the best of our knowledge, the present study is the first to examine the relationship between BR consumers and firms' certification behaviors in order to explain, in depth, the causes behind the failure of voluntary certification.

\section{The Model}

We consider a model that includes two identical potential entrants to the market. Firm $L$ (for brown or bad), located at position 0 , provides low-quality agricultural products, while firm $H$ (for green or good), located at position 1, provides high-quality agricultural products. Each firm fully knows the real quality of its products and that of its competitor. However, the credence aspect of quality is not observable to consumers before their purchase. Firms can rely on a voluntary certification program to differentiate their products against its competitor's products, which are uncertificated, and benefit from their consumers' trust of quality and increased market volume. Without loss of generality, we let the product cost of firm $L$ and firm $H$ be $c$ and $c+\Delta c(c>0, \Delta c>0)$, price be $p_{L}$ and $p_{L}\left(p_{H}>p_{L}>0\right)$, and each consumer's value of the low- and high-quality products be $v$ and $v+\Delta v(v>0, \Delta v>0)$. To ensure that consumers are willing to buy the high-quality products, we must have $\Delta v>p_{H}-p_{L}$.

Firms pursue certification if they believe that the benefits of certification outweigh the corresponding costs. In line with Ibanez and Grolleau [23], we assume that the certification is not perfect, but deterministic, in the sense that firms would be awarded the label for sure if they ask for certification, yet brown firms have to bear a higher certification cost. This seems to be a more realistic approach. Consumers differ in the information about the certification systems. Similar to Shulman and Geng [18], we state that a proportion $\theta \in(0,1]$ of consumers (i.e., BR consumers) presents a lack of awareness of certification logos on packages and cannot detect the mislabeling problems. Therefore, they believe that the certified (uncertified) products are of high (low) quality. For example, some evidence indicates that many rural Chinese consumers are still unaware of the certificating logos of organic products and or other logos from other quality management systems. In addition, a proportion 
$1-\theta$ of consumers (i.e., $\mathrm{CR}$ consumers) are aware of these certificating logos and are aware of what they imply with respect to the products they label. Consumers are uniformly located along the interval [0,1], while $t$ denotes consumers' transportation costs. Similar to the models of Villas-Boas [24] and Shin and Sudhir [25], we assume that $v$ is sufficiently high to cover the whole market. The market structure is shown in Figure 1.

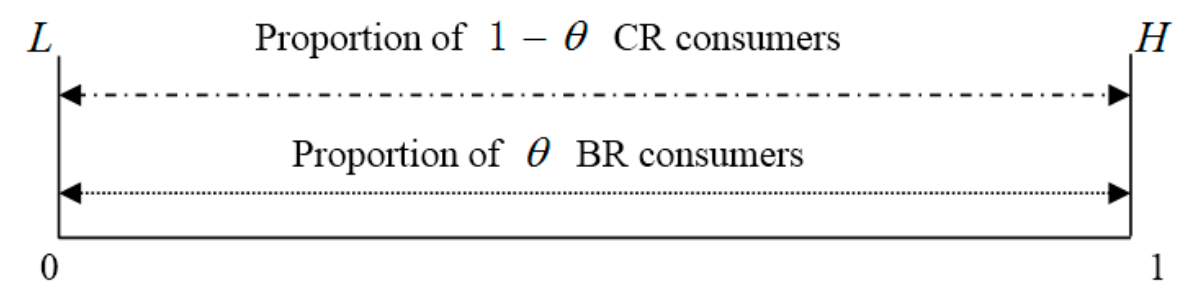

Figure 1. Market structure.

Voluntary certification means that both firms can apply for certification of their own accord. If a firm opts for certification, it has to pay a certification cost (denoted as $c_{e}$ ) to the certifier. For the low-quality firm, a catch-up cost (denoted as $c_{t}$ ) of certification should be paid in addition to $c_{e}$. If firm $L$ is willing to apply for certification, we must have $p_{H}-p_{L}>c_{e}+c_{d}$. We let $N N$ (non-certification/non-certification) denote the situation when neither firm opts for certification, NC (non-certification/certification) when only firm $H$ opts for certification, $C N$ when only firm $L$ opts for certification, and $C C$ when both firms opt for certification; $B$ denotes BR consumers and $K$ denotes $\mathrm{CR}$ consumers, while $\pi$ denotes firm profit. The payoff matrix of the firms' behavioral interactions is shown in Table 1.

Table 1. Payoff matrix of the firms' behavioral interactions.

\begin{tabular}{lcc}
\hline & Firm $L$ Does Not Opt for Certification & Firm $L$ Opts for Certification \\
\hline Firm $H$ does not opt for certification & $\pi_{H}^{N N}, \pi_{L}^{N N}$ & $\pi_{H}^{N C}, \pi_{L}^{N C}$ \\
\hline Firm $H$ opts for certification & $\pi_{H}^{C N}, \pi_{L}^{C N}$ & $\pi_{H}^{C C}, \pi_{L}^{C C}$ \\
\hline
\end{tabular}

Furthermore, we let $x_{j}^{m}(j=B, K ; m=N N, C N, N C, C C)$ indicate the undifferentiated utility point where consumer $j$ buys an agricultural product from both firms. It is easy to verify that, no matter whether both firms opt for certification or not, the expected utility of the CR consumer obtained from firm $L$ is always $v-t x_{K}^{m}-p_{L}^{m}$ and that from firm $H$ is always $v+\Delta v-t\left(1-x_{K}^{m}\right)-p_{H}^{m}$. When the expected utilities of the $\mathrm{CR}$ consumer buying agricultural products from firm $L$ and firm $H$ are equal, we must have $v-t x_{K}^{m}-p_{L}^{m}=v+\Delta v-t\left(1-x_{K}^{m}\right)-p_{H}^{m}$, meaning that the undifferentiated utility is $x_{K}^{m}=\frac{1}{2}+\frac{p_{H}-p_{L}-\Delta v}{2 t}$. We can thus infer that CR consumers located at $x \leq x_{K}^{m}$ will buy agricultural products from firm $L$ and those located at $x>x_{K}^{m}$ will buy agricultural products from firm $H$.

\subsection{Neither Firm Opts for Certification (NN)}

When neither firm $L$ nor firm $H$ opt for certification, given the prices $p_{L}^{N N}$ and $p_{H}^{N N}$, the utilities of BR consumers buying agricultural products from both firms are $v-t x_{B}^{N N}-p_{L}^{N N}$ and $v-t\left(1-x_{B}^{N N}\right)-p_{H}^{N N}$, respectively. Hence, the undifferentiated utility point is $x_{B}^{N N}=\frac{1}{2}+\frac{p_{H}^{N N}-p_{L}^{N N}}{2 t}$. The market shares of firm $L$ and firm $H$ can be given by

$$
\begin{gathered}
q_{L}^{N N}=\theta x_{B}^{N N}+(1-\theta) x_{K}^{N N}=\frac{1}{2}+\frac{p_{H}^{N N}-p_{L}^{N N}-(1-\theta) \Delta v}{2 t} \\
q_{H}^{N N}=\theta\left(1-x_{B}^{N N}\right)+(1-\theta)\left(1-x_{K}^{N N}\right)=\frac{1}{2}-\frac{p_{H}^{N N}-p_{L}^{N N}-(1-\theta) \Delta v}{2 t}
\end{gathered}
$$


The profit functions of the two firms are

$$
\pi_{L}^{N N}=\left(p_{L}^{N N}-c\right) q_{L}^{N N} \text { and } \pi_{H}^{N N}=\left(p_{H}^{N N}-c-\Delta c\right) q_{H}^{N N}
$$

By applying the first-order condition, the sales prices of both firms are

$$
\begin{aligned}
& p_{L}^{N N *}=\frac{3 t-(1-\theta) \Delta v+3 c+\Delta c}{3} \\
& p_{H}^{N N *}=\frac{3 t+(1-\theta) \Delta v+3 c+2 \Delta c}{3}
\end{aligned}
$$

Therefore, their profits are

$$
\begin{aligned}
& \pi_{L}^{N N *}=\frac{t}{2}-\frac{(1-\theta) \Delta v-\Delta c}{3}+\frac{[(1-\theta) \Delta v-\Delta c]^{2}}{18 t} \\
& \pi_{H}^{N N *}=\frac{t}{2}+\frac{(1-\theta) \Delta v-\Delta c}{3}+\frac{[(1-\theta) \Delta v-\Delta c]^{2}}{18 t}
\end{aligned}
$$

\subsection{Only Firm H Opts for Certification (NC)}

When firm $L$ does not opt for certification but firm $H$ does, the utilities of the BR consumer buying agricultural products from both firms are $v-t x_{B}^{N C}-p_{L}^{N C}$ and $v+\Delta v-t\left(1-x_{B}^{N C}\right)-p_{H}^{N C}$, respectively. Therefore, in this situation, the undifferentiated utility point is $x_{B}^{N C}=\frac{1}{2}+\frac{p_{H}^{N C}-p_{L}^{N C}-\Delta v}{2 t}$. The market shares of firm $L$ and firm $H$ can be given by

$$
\begin{gathered}
q_{L}^{N C}=\theta x_{B}^{N C}+(1-\theta) x_{K}^{N C}=\frac{1}{2}+\frac{p_{H}^{N C}-p_{L}^{N C}-\Delta v}{2 t} \\
q_{H}^{N C}=\theta\left(1-x_{B}^{N C}\right)+(1-\theta)\left(1-x_{K}^{N C}\right)=\frac{1}{2}-\frac{p_{H}^{N C}-p_{L}^{N C}-\Delta v}{2 t}
\end{gathered}
$$

The profit functions of the two firms are

$$
\pi_{L}^{N C}=\left(p_{L}^{N C}-c\right) q_{L}^{N C} \text { and } \pi_{H}^{N C}=\left(p_{H}^{N C}-c-\Delta c-c_{e}\right) q_{H}^{N C}
$$

By applying the first-order condition, the sales prices are

$$
\begin{gathered}
p_{L}^{N C *}=\frac{3 t-\Delta v+3 c+\Delta c+c_{e}}{3} \\
p_{H}^{N C *}=\frac{3 t+\Delta v+3 c+2 \Delta c+2 c_{e}}{3}
\end{gathered}
$$

Therefore, their profits are

$$
\begin{aligned}
& \pi_{L}^{N C *}=\frac{t}{2}-\frac{\Delta v-\Delta c-c_{e}}{3}+\frac{\left(\Delta v-\Delta c-c_{e}\right)^{2}}{18 t} \\
& \pi_{H}^{N C *}=\frac{t}{2}+\frac{\Delta v-\Delta c-c_{e}}{3}+\frac{\left(\Delta v-\Delta c-c_{e}\right)^{2}}{18 t}
\end{aligned}
$$

\subsection{Only Firm L Opts for Certification (CN)}

When firm $H$ does not opt for certification but firm $L$ does, the utilities of the BR consumer buying agricultural products from both firms are $v+\Delta v-t x_{B}^{C N}-p_{L}^{C N}$ and $v-t\left(1-x_{B}^{C N}\right)-p_{H}^{C N}$, 
respectively. Therefore, in this situation, the undifferentiated utility point is $x_{B}^{C N}=\frac{1}{2}+\frac{p_{H}^{C N}-p_{L}^{C N}+\Delta v}{2 t}$. The market shares of firm $L$ and firm $H$ can be given by

$$
\begin{gathered}
q_{L}^{C N}=\theta x_{B}^{C N}+(1-\theta) x_{K}^{C N}=\frac{1}{2}+\frac{p_{H}^{C N}-p_{L}^{C N}+(2 \theta-1) \Delta v}{2 t} \\
q_{H}^{C N}=\theta\left(1-x_{B}^{C N}\right)+(1-\theta)\left(1-x_{K}^{C N}\right)=\frac{1}{2}-\frac{p_{H}^{C N}-p_{L}^{C N}+(2 \theta-1) \Delta v}{2 t}
\end{gathered}
$$

The profit functions of the two firms are

$$
\pi_{L}^{C N}=\left(p_{L}^{C N}-c-c_{e}-c_{d}\right) q_{L}^{C N} \text { and } \pi_{H}^{C N}=\left(p_{H}^{C N}-c-\Delta c\right) q_{H}^{C N}
$$

By applying the first-order condition, the sales prices are

$$
\begin{aligned}
& p_{L}^{C N *}=\frac{3 t+(2 \theta-1) \Delta v+3 c+2 c_{d}+2 c_{e}+\Delta c}{3} \\
& p_{H}^{C N *}=\frac{3 t-(2 \theta-1) \Delta v+3 c+2 \Delta c+c_{e}+c_{d}}{3}
\end{aligned}
$$

Therefore, their profits are

$$
\begin{aligned}
& \pi_{L}^{C N *}=\frac{t}{2}-\frac{(1-2 \theta) \Delta v-\Delta c+c_{e}+c_{d}}{3}+\frac{\left[(1-2 \theta) \Delta v-\Delta c+c_{e}+c_{d}\right]^{2}}{18 t} \\
& \pi_{H}^{C N *}=\frac{t}{2}+\frac{(1-2 \theta) \Delta v-\Delta c+c_{e}+c_{d}}{3}+\frac{\left[(1-2 \theta) \Delta v-\Delta c+c_{e}+c_{d}\right]^{2}}{18 t}
\end{aligned}
$$

\subsection{Firm L and Firm H Opt for Certification (CC)}

When firm $L$ and firm $H$ both opt for certification (CC), the utilities of the BR consumer buying agricultural products from both firms are $v+\Delta v-t x_{B}^{C C}-p_{L}^{C C}$ and $v+\Delta v-t\left(1-x_{B}^{C C}\right)-p_{H}^{C C}$, respectively. Therefore, in this situation, the undifferentiated utility point is $x_{B}^{C C}=\frac{1}{2}+\frac{p_{H}^{C C}-p_{L}^{C C}}{2 t}$. The market shares of firm $L$ and firm $H$ can be given by

$$
\begin{gathered}
q_{L}^{C C}=\theta x_{B}^{C C}+(1-\theta) x_{K}^{C C}=\frac{1}{2}+\frac{p_{H}^{C C}-p_{L}^{C C}-(1-\theta) \Delta v}{2 t} \\
q_{H}^{C C}=\theta\left(1-x_{B}^{C C}\right)+(1-\theta)\left(1-x_{K}^{C C}\right)=\frac{1}{2}-\frac{p_{H}^{C C}-p_{L}^{C C}-(1-\theta) \Delta v}{2 t}
\end{gathered}
$$

The profit functions of the two firms are

$$
\pi_{L}^{C C}=\left(p_{L}^{C C}-c-c_{e}-c_{d}\right) q_{L}^{C C}, \pi_{H}^{C C}=\left(p_{H}^{C C}-c-\Delta c-c_{e}\right) q_{H}^{C C}
$$

By applying the first-order condition, the sales prices are

$$
\begin{aligned}
& p_{L}^{C C *}=\frac{3 t-(1-\theta) \Delta v+3 c+\Delta c+3 c_{e}+2 c_{d}}{3} \\
& p_{H}^{C C *}=\frac{3 t+(1-\theta) \Delta v+3 c+2 \Delta c+3 c_{e}+c_{d}}{3}
\end{aligned}
$$

Therefore, their profits are

$$
\pi_{L}^{C C *}=\frac{t}{2}-\frac{c_{d}+(1-\theta) \Delta v-\Delta c}{3}+\frac{\left[c_{d}+(1-\theta) \Delta v-\Delta c\right]^{2}}{18 t}
$$




$$
\pi_{H}^{C C} *=\frac{t}{2}+\frac{c_{d}+(1-\theta) \Delta v-\Delta c}{3}+\frac{\left[c_{d}+(1-\theta) \Delta v-\Delta c\right]^{2}}{18 t}
$$

By analyzing the monotonicity of market shares and sales prices among these four combinations of certification behavior, we get

$$
\begin{gathered}
\frac{\partial q_{L}^{m *}}{\partial \theta}>0, \frac{\partial q_{H}^{m *}}{\partial \theta}<0, \frac{\partial p_{L}^{m *}}{\partial \theta}>0, \frac{\partial p_{H}^{m *}}{\partial \theta}<0, \frac{\partial \pi_{L}^{m *}}{\partial \theta}>0, \frac{\partial \pi_{H}^{m *}}{\partial \theta}<0(m=N N, C N, C C) \\
\frac{\partial q_{L}^{N C *}}{\partial \theta}=0, \frac{\partial q_{H}^{N C *}}{\partial \theta}=0, \frac{\partial p_{L}^{N C *}}{\partial \theta}=0, \frac{\partial p_{H}^{N C *}}{\partial \theta}=0, \frac{\partial \pi_{L}^{N C *}}{\partial \theta}=0, \frac{\partial \pi_{H}^{N C *}}{\partial \theta}=0 .
\end{gathered}
$$

Therefore, we can obtain Proposition 1.

Proposition 1. In the situations NN, CN, and CC, as the proportion of BR consumers increases, the market share, sales price, and profit of the low-quality firm will increase, but those of the high-quality firm will decrease. By contrast, in the situation NC, changes are unrelated to the proportion of BR consumers.

\section{Results and Equilibrium Analysis}

In this section, we compare the market shares, sales prices, and profits in different situations to analyze the relationship between the proportion of BR consumers and market equilibrium.

\subsection{Comparison of Market Shares}

Analyzing the market shares for the four combinations of certification behaviors (as shown in Table 2) allows us to obtain Propositions 2 and 3. First, we have $\theta^{*}=\frac{\mathcal{c}_{e}}{\Delta v}, \theta^{* *}=\frac{\mathcal{c}_{e}}{\Delta v}+\frac{c_{d}}{2 \Delta v}$ and $\theta^{* * *}=\frac{c_{e}}{\Delta v}+\frac{c_{d}}{\Delta v}$. Because $\Delta v>p_{H}-p_{L}$ and $p_{H}-p_{L}>c_{e}+c_{d}$ as stated above, we can easily infer $\Delta v>c_{e}+c_{d}$, and then we get $0<\theta^{*}<\theta^{* *}<\theta^{* * *}<1$.

Table 2. Firms' market shares for the four combinations of certification behaviors.

\begin{tabular}{ccccc}
\hline & $N N$ & $C C$ & $C N$ & $N C$ \\
\hline$q_{L}^{m *}$ & $\frac{1}{2}+\frac{\Delta c-\Gamma}{6 t}$ & $\frac{1}{2}+\frac{\Delta c-c_{d}-\Phi}{6 t}$ & $\frac{1}{2}+\frac{\Delta c-c_{e}-c_{d}+\Psi}{6 t}$ & $\frac{1}{2}+\frac{\Delta c+c_{e}-\Delta v}{6 t}$ \\
\hline$q_{H}^{m *}$ & $\frac{1}{2}-\frac{\Delta c-\Gamma}{6 t}$ & $\frac{1}{2}-\frac{\Delta c-c_{d}-\Phi}{6 t}$ & $\frac{1}{2}-\frac{\Delta c-c_{e}-c_{d}+\Psi}{6 t}$ & $\frac{1}{2}-\frac{\Delta c+c_{e}-\Delta v}{6 t}$ \\
\hline \multicolumn{5}{c}{ Notes: $\Gamma=(1-\theta) \Delta v, \Phi=(1-\theta) \Delta v, \Psi=(2 \theta-1) \Delta v}$.
\end{tabular}

Proposition 2. If $\theta \in\left(0, \theta^{*}\right]$, then $q_{L}^{C N *}<q_{L}^{C C *}<q_{L}^{N N *}<q_{L}^{N C *}$; if $\theta \in\left(\theta^{*}, \theta^{* *}\right]$, then $q_{L}^{C C *}<q_{L}^{C N *}<q_{L}^{N C *}<q_{L}^{N N *}$; if $\theta \in\left(\theta^{* *}, \theta^{* * *}\right]$, then $q_{L}^{C C *}<q_{L}^{N C *}<q_{L}^{C N *}<q_{L}^{N N *}$; if $\theta \in\left(\theta^{* * *}, 1\right]$, then $q_{L}^{N C *}<q_{L}^{C C *}<q_{L}^{N N *}<q_{L}^{C N *}$.

Proposition 3. If $\theta \in\left(0, \theta^{*}\right]$, then $q_{H}^{N C *}<q_{H}^{N N *}<q_{H}^{C C *}<q_{H}^{C N *}$; if $\theta \in\left(\theta^{*}, \theta^{* *}\right]$, then $q_{H}^{N N *}<q_{H}^{N C *}<q_{H}^{C N *}<q_{H}^{C C *}$; if $\theta \in\left(\theta^{* *}, \theta^{* * *}\right]$, then $q_{H}^{N N *}<q_{H}^{C N *}<q_{H}^{N C *}<q_{H}^{C C *}$; if $\theta \in\left(\theta^{* * *}, 1\right]$, then $q_{H}^{C N *}<q_{H}^{N N *}<q_{H}^{C C *}<q_{H}^{N C *}$.

Propositions 2 and 3 state that if the proportion of BR consumers is relatively low, in the situation when one firm opts for voluntary certification but the other does not, the market share of the former firm is always lower than that in the other three situations. If the proportion of BR consumers is relatively high, by contrast, the market share of the former firm is always higher. If the proportion of BR consumers is not extreme, in the situation when both firms opt for voluntary certification (neither firm opts for certification), the market share of the high-quality firm is always higher (lower). In summary, if the proportion of BR consumers is relatively high (low), in the situation when one firm opts for voluntary certification and the other does not, the market share of the former firm is always higher (lower) than that in the other three situations. 


\subsection{Comparison of Sales Prices}

Analyzing the sales prices for the four combinations of certification behaviors (as shown in Table 3) allows us to obtain Propositions 4 and 5.

Proposition 4. If $\theta \in\left(0, \theta^{*}\right]$, then $p_{L}^{C C *} \geq p_{L}^{C N *}>p_{L}^{N C *} \geq p_{L}^{N N *}$; if $\theta \in\left(\theta^{*}, 1\right]$, then $p_{L}^{C N *}>p_{L}^{C C *}>$ $p_{L}^{N N *}>p_{L}^{N C *}$.

Proposition 5. If $\theta \in\left(0, \theta^{* * *}\right]$, then $p_{H}^{C C *} \geq p_{H}^{N C *}>p_{H}^{C N *} \geq p_{H}^{N N *}$; if $\theta \in\left(\theta^{* * *}, 1\right]$, then $p_{H}^{N C *}>p_{H}^{C C *}>$ $p_{H}^{N N *}>p_{H}^{C N *}$.

Table 3. Firms' sales prices for the four combinations of certification behaviors.

\begin{tabular}{ccccc}
\hline & $N N$ & $N C$ & $C N$ & $C C$ \\
\hline$p_{L}^{m *}$ & $\frac{\Lambda-\Omega}{3}$ & $\frac{\Lambda-\Delta v+c_{e}}{3}$ & $\frac{\Lambda-\Omega+2 M+\theta \Delta v}{3}$ & $\frac{\Lambda-\Omega+2 M+c_{e}}{3}$ \\
\hline$p_{H}^{m *}$ & $\frac{\Lambda+\Omega+\Delta c}{3}$ & $\frac{\Lambda+\Delta c+\Delta v+2 c_{e}}{3}$ & $\frac{\Lambda+\Omega+2 M+\Delta c-\theta \Delta v}{3}$ & $\frac{\Lambda+\Omega+M+\Delta c+2 c_{e}}{3}$ \\
\hline \multicolumn{5}{r}{ Note: $\Lambda=3 t+3 c+\Delta c, \Omega=(1-\theta) \Delta v, M=c_{e}+c_{d}}$.
\end{tabular}

Propositions 4 and 5 state that if the proportion of BR consumers is relatively low (high), regardless of whether firms are low or high quality, their sales prices will be higher (lower) than those in the other three situations when in the situation that both firms opt for certification, and lower (higher) than those in the other three situations when neither firm does so (as shown in Figures 2 and 3).

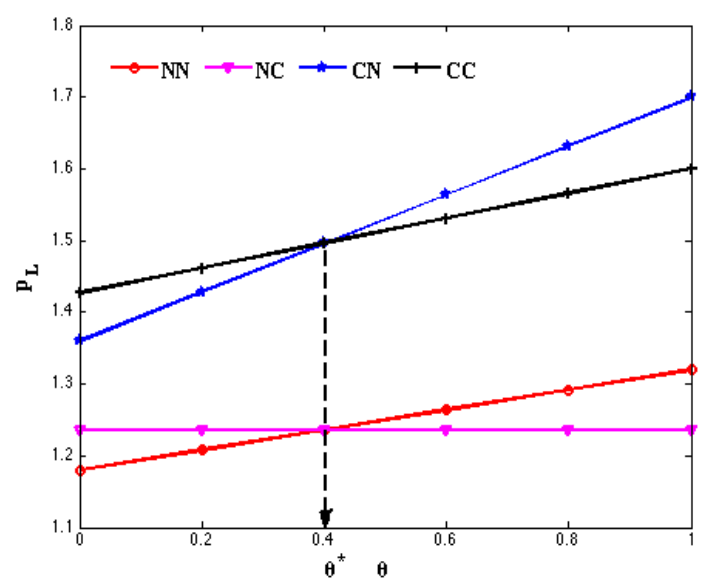

Figure 2. Sales price of firm $L$.

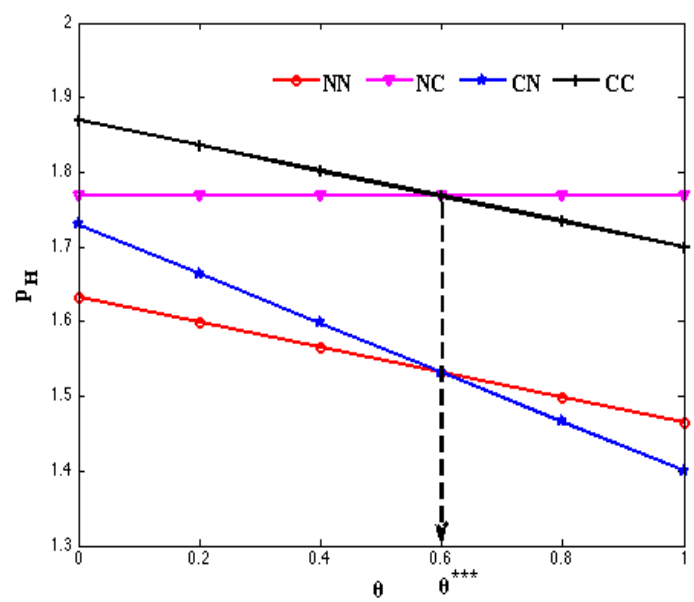

Figure 3. Sales price of firm $H$. 


\subsection{Comparison of Firms' Profits and Analysis of the Market Equilibrium}

Analyzing the firms' profits for the four combinations of certification behaviors (as shown in Figure 3) allows us to obtain Propositions 6 and 7.

Proposition 6. If $\theta \in\left(0, \theta^{*}\right]$, then $\pi_{L}^{C N *}<\pi_{L}^{C C *}<\pi_{L}^{N N *}<\pi_{L}^{N C *}$; if $\theta \in\left(\theta^{*}, \theta^{* *}\right]$, then $\pi_{L}^{C C *}<\pi_{L}^{C N *}<\pi_{L}^{N C *}<\pi_{L}^{N N *}$; if $\theta \in\left(\theta^{* *}, \theta^{* * *}\right]$, then $\pi_{L}^{C C *}<\pi_{L}^{N C *}<\pi_{L}^{C N *}<\pi_{L}^{N N *}$; if $\theta \in\left(\theta^{* * *}, 1\right]$, then $\pi_{L}^{N C *}<\pi_{L}^{C C *}<\pi_{L}^{N N *}<\pi_{L}^{C N *}$.

Proposition 7. If $\theta \in\left(0, \theta^{*}\right]$, then $\pi_{H}^{N C *}<\pi_{H}^{N N *}<\pi_{H}^{C C *}<\pi_{H}^{C N *}$; if $\theta \in\left(\theta^{*}, \theta^{* *}\right]$, then $\pi_{H}^{N N *}<\pi_{H}^{N C *}<\pi_{H}^{C N *}<\pi_{H}^{C C *}$; if $\theta \in\left(\theta^{* *}, \theta^{* * *}\right]$, then $\pi_{H}^{N N *}<\pi_{H}^{C N *}<\pi_{H}^{N C *}<\pi_{H}^{C C *}$; if $\theta \in\left(\theta^{* * *}, 1\right]$, then $\pi_{H}^{C N *}<\pi_{H}^{N N *}<\pi_{H}^{C C *}<\pi_{H}^{N C *}$.

The complete proof of Propositions 6 and 7 is presented in the Appendix A.

Table 4 summarizes the firms' profits for the four combinations of certification behaviors. From further analysis, we find that because $\pi_{L}^{C N *}<\pi_{L}^{N N *}$ and $\pi_{L}^{C C *}<\pi_{L}^{N C *}$, when $\theta \in\left(0, \theta^{*}\right]$, "does not opt for certification" is firm $L$ 's strictly dominant strategy. However, when firm $L$ does not apply for certification, the profit of firm $H$ with certification is $\pi_{H}^{N C *}$ and that without certification is $\pi_{H}^{N N *}$, because $\pi_{H}^{N N *}>\pi_{H}^{N C *}$. Hence, firm $H$ will not apply for certification, and the market equilibrium is now $N N$. Further, if $\theta \in\left(\theta^{*}, \theta^{* * *}\right]$, the market equilibrium is $N C$; however, if $\theta \in\left(\theta^{* * *}, 1\right]$, the market equilibrium is CC. Consequently, we can obtain Inference 1.

Table 4. Firms' profits for the four combinations of certification behaviors. Notes: $D=(1-\theta) \Delta v-\Delta c$, $E=(1-\theta) \Delta v-\Delta c+c_{d}, F=(1-2 \theta) \Delta v-\Delta c+c_{e}+c_{d}, G=\Delta v-\Delta c-c_{e}$.

\begin{tabular}{ccccc}
\hline & $N N$ & $C C$ & $C N$ & $N C$ \\
\hline$\pi_{L}^{m *}$ & $\frac{t}{2}-\frac{D}{3}+\frac{D^{2}}{18 t}$ & $\frac{t}{2}-\frac{E}{3}+\frac{E^{2}}{18 t}$ & $\frac{t}{2}-\frac{F}{3}+\frac{F^{2}}{18 t}$ & $\frac{t}{2}-\frac{G}{3}+\frac{G^{2}}{18 t}$ \\
\hline$\pi_{H}^{m *}$ & $\frac{t}{2}+\frac{D}{3}+\frac{D^{2}}{18 t}$ & $\frac{t}{2}+\frac{E}{3}+\frac{E^{2}}{18 t}$ & $\frac{t}{2}+\frac{F}{3}+\frac{F^{2}}{18 t}$ & $\frac{t}{2}+\frac{G}{3}+\frac{G^{2}}{18 t}$ \\
\hline
\end{tabular}

Inference 1. If the proportion of $\mathrm{BR}$ consumers is relatively lower (higher) than that of $\mathrm{CR}$ consumers, firm $\mathrm{L}$ and firm $\mathrm{H}$ will reach the pooling equilibrium, $\mathrm{NN}(\mathrm{CC})$. However, if the proportion of BR consumers is not extreme, firm $\mathrm{L}$ and firm $\mathrm{H}$ will reach the separating equilibrium, $\mathrm{NC}$.

\section{Numerical Example}

According to the theory of information economics, any signal transmission mechanism that can correctly separate product quality is deemed to be socially effective. Against this background, this section presents the analysis of consumers' actual total utility for the four combinations of certification behaviors to discuss the relationship between the proportion of BR consumers and the effectiveness of the certification mechanism. Here, we make $v=1.50, \Delta v=0.50, c=0.60, \Delta c=0.40$, $t=0.60, c_{e}=0.20$, and $c_{d}=0.10$; consumers' actual total utility is thus $U^{m *}(m=N N, N C, C C)$, $U^{m *}=\left(v-p_{L}^{m *}\right)\left(x_{B}^{m *}+x_{K}^{m *}\right)+\left(v+\Delta v-p_{H}^{m *}\right)\left(2-x_{B}^{m *}-x_{K}^{m *}\right)$.

We can easily obtain $\theta^{*}=0.4$ and $\theta^{* * *}=0.6$ if firm $L$ and firm $H$ reach the separating equilibrium, $N C$, regardless of the proportion of BR consumers; hence, consumers' actual total utility $U^{N C *}=0.5019$.

If $\theta \in(0,0.4]$, firm $L$ and firm $H$ reach the pooling equilibrium, $N N$. We make $\theta$ from 0 to 0.40 with a step of 0.05 . Figure 4 compares consumers' actual total utility at the pooling equilibrium with that at the ideal separating equilibrium. 


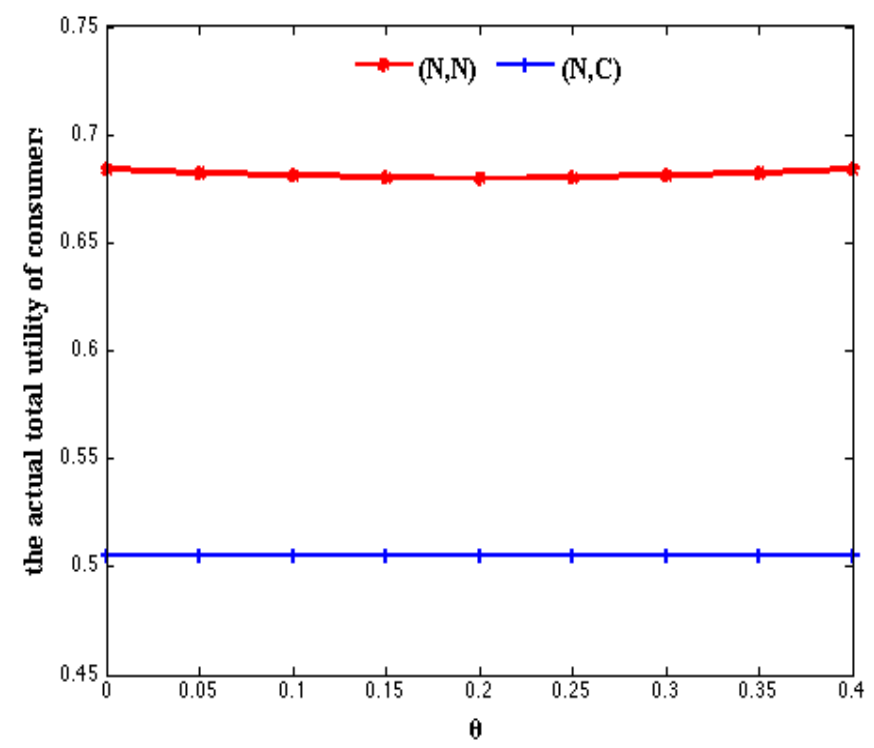

Figure 4. Comparison of consumers' actual total utility if $\theta \in(0,0.4]$.

If $\theta \in(0.4,0.6)$, firm $L$ and firm $H$ reach the separating equilibrium, $N C$. The result is social effectiveness. If $\theta \in(0.6,1]$, firm $L$ and firm $H$ reach the pooling equilibrium, $C C$. We make $\theta$ from 0.60 to 1 with a step of 0.05 . Figure 5 compares consumers' actual total utility at the pooling equilibrium with that at the ideal separating equilibrium.

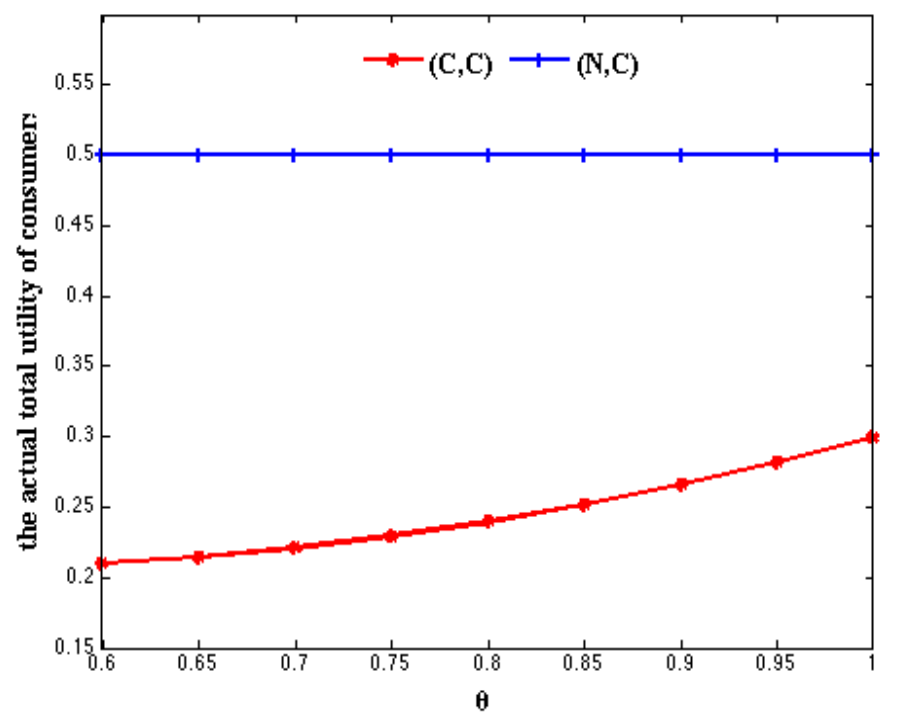

Figure 5. Comparison of consumers' actual total utility if $\theta \in(0.6,1]$.

Therefore, we find that if and only if the proportion of BR consumers is not extreme, the voluntary certification mechanism can help firms reach the perfect separating equilibrium. If the proportion of BR consumers is relatively low, the agricultural product market only can reach the pooling equilibrium, $N N$, and thus the voluntary certification mechanism loses effectiveness. However, because of the existence of $C R$ consumers, firm $H$ need not reduce the degree of information asymmetry in the agricultural product market through certification and thus social efficiency is higher than that at the separating equilibrium.

On the contrary, if the proportion of BR consumers is relatively high, the market can only reach the pooling equilibrium, $C C$ and thus the voluntary certification mechanism again loses effectiveness. 
However, because of the existence of BR consumers, firm $L$ is willing incur the additional cost to opt for certification in order to disguise itself as a high-quality firm. This improves the degree of information asymmetry in the market and thus social efficiency is lower than that at the separating equilibrium.

\section{Conclusions}

The agricultural product certification mechanism is an important way to alleviate the information asymmetry between consumers and firms, which transfers relevant laws, regulations, standards, and technical specifications besides the production and processing safety process, in the form of public evaluation results. Based on the hypothesis of a duopoly, this study focused on how the relative proportion of BR consumers influences the effectiveness of the voluntary certification mechanisms in the agricultural industry. Our results provide a new explanation of why voluntary certification in this sector does not function well.

In particular, the presented findings allow us to draw the following three managerial insights. First, a change in the proportion of BR consumers leads to different combinations of certification behaviors. Second, if the proportion of BR consumers is lower or higher than that of $\mathrm{CR}$ consumers, the agricultural market cannot reach the ideal separating equilibrium and thus the voluntary certification mechanism loses effectiveness. Finally, if the proportion of BR consumers is higher, the agricultural market cannot improve social effectiveness.

Moreover, these findings are potentially helpful to decision-makers in different circumstances. It is evident that the effectiveness and reliability of the whole certification system strongly depended on the type of external audits and their implementation. Therefore, one primary practical implication of this study is that the fraud activities of mislabeling are able to be identified by public authorities and organizations with the proposed inspection mechanism in this paper. We further conclude that the inspecting/testing results should be transferred to consumers via all kinds of media. Based on the occupied information of inspecting/testing results it is revealed that, by third-party or authority sectors, firms' reputations are gradually built up, which strongly affects consumers' intuitive evaluation of the quality of the agro-products. Since consumers' purchasing willingness directly and positively links to the firm's reputation, timely disclosure of inspecting/testing information is extremely important to the regulation of agro-products. Secondly, the firms with high-quality products are encouraged to undertake activities to enhance the consumers' awareness of certification logos according to our findings in this paper. We analytically identify that although certification potentially benefits the high-quality firms, it is most probably profitable to high-quality firms if the relation between certification logos and product quality are impressed to consumers. Finally, we recommend that consumers, recognizing their imperfect rationality, should seek advice and consult experts before making certain purchases to limit the mistakes that they make.

Despite this study's contributions, it has several limitations. Some limitations of our work arise from the simplicity of the proposed model, which ignores the probability of a firm being certified. Current certification technology and regulatory degree, which were omitted from the presented analysis, should also be considered in future research on this topic. In addition, considering firms' fairness preferences would also be an interesting point that deserves further attention. In a more general model, when high-quality firms cannot achieve suitable profits, they may generate a negative utility of unfairness.

Acknowledgments: The work was supported by the National Natural Science Foundation of China under research project number 71371086 and the Fundamental Research Funds for the Central Universities under research project number JUSRP51416B.

Author Contributions: These authors contributed equally to this work. All authors read and approved the final version.

Conflicts of Interest: The authors declare no conflict of interest. 


\section{Appendix A. Proof of Propositions 6 and 7}

By comparing the firms' profits for the four combinations of certification behaviors, we find that

(1) $\pi_{L}^{N N *}-\pi_{L}^{N C *}=\frac{\left(\theta \Delta v-c_{e}\right)\left[6 t-(2-\theta) \Delta v+2 \Delta c+c_{e}\right]}{18 t}$, because $q_{L}^{N N *}>0$ and $q_{L}^{N C *}>0$; that is, $6 t-(2-\theta) \Delta v+2 \Delta c+c_{e}>0$. Hence, the plus or minus characteristic of $\pi_{L}^{N N *}-\pi_{L}^{N C *}$ depends on $\theta \Delta v-c_{e}$. If $\theta \leq \theta^{*}$, meaning that $\pi_{L}^{N N *} \leq \pi_{L}^{N C *}$; if $\theta>\theta^{*}$, then $\pi_{L}^{N N *}>\pi_{L}^{N C *}$.

(2) $\pi_{L}^{C N *}-\pi_{L}^{N C *}=\frac{\left[2 \theta \Delta v-2 c_{e}-c_{d}\right]\left[6 t-(2-2 \theta) \Delta v+2 \Delta c-c_{d}\right]}{18 t}$; likewise, the plus or minus characteristic of $\pi_{L}^{C N *}-\pi_{L}^{N C *}$ depends on $2 \theta \Delta v-2 c_{e}-c_{d}$. If $\theta \leq \theta^{* *}$, then $\pi_{L}^{C N *} \leq \pi_{L}^{N C *}$; if $\theta>\theta^{* *}$, then $\pi_{L}^{C N *}>\pi_{L}^{N C *}$.

(3) $\pi_{L}^{C N *}-\pi_{L}^{C C *}=\frac{\left(\theta \Delta v-c_{e}\right)\left[6 t-(2-3 \theta) \Delta v+2 \Delta c-2 c_{d}-c_{e}\right]}{18 t}$; likewise, the plus or minus characteristic of $\pi_{L}^{C N *}-\pi_{L}^{C C *}$ depends on $\theta \Delta v-c_{e}$. If $\theta \leq \theta^{*}$, then $\pi_{L}^{C N *} \leq \pi_{L}^{C C *}$; if $\theta>\theta^{*}$, then $\pi_{L}^{C N *}>\pi_{L}^{C C *}$.

(4) $\pi_{L}^{C N *}-\pi_{L}^{N N *}=\frac{\left(\theta \Delta v-c_{e}-c_{d}\right)\left[6 t-(2-3 \theta) \Delta v+2 \Delta c-c_{e}-c_{d}\right]}{18 t}$; likewise, the plus or minus characteristic of $\pi_{L}^{C N *}-\pi_{L}^{N N *}$ depends on $\theta \Delta v-c_{e}-c_{d}$. If $\theta \leq \theta^{* * *}$, then $\pi_{L}^{C N *} \leq \pi_{L}^{N N *}$; if $\theta>\theta^{* * *}$, then $\pi_{L}^{C N *}>\pi_{L}^{N N *}$.

(5) $\pi_{L}^{C C *}-\pi_{L}^{N C *}=\frac{\left(\theta \Delta v-c_{e}-c_{d}\right)\left[6 t-(2-\theta) \Delta v+2 \Delta c+c_{e}-c_{d}\right]}{18 t}$; likewise, the plus or minus characteristic of $\pi_{L}^{C C *}-\pi_{L}^{N C *}$ depends on $\theta \Delta v-c_{e}-c_{d}$. If $\theta \leq \theta^{* * *}$, then $\pi_{L}^{C C *} \leq \pi_{L}^{N C *}$; if $\theta>\theta^{* * *}$, then $\pi_{L}^{C C *}>\pi_{L}^{N C *}$.

(6) $\pi_{L}^{N N *}-\pi_{L}^{C C *}=\frac{c_{d}\left[6 t-2(1-\theta) \Delta v+2 \Delta c-c_{d}\right]}{18 t}$; because $q_{L}^{N N *}>0$ and $q_{L}^{C C *}>0$, we can easily know $6 t-2(1-\theta) \Delta v+2 \Delta c-c_{d}>0$; then, $\pi_{L}^{N N *}>\pi_{L}^{C C *}$ always holds.

\section{References}

1. Nelson, P. Information and Consumer Behavior. J. Political Econ. 1970, 78, 311-329. [CrossRef]

2. Nelson, P. Advertising as Information. J. Political Econ. 1974, 82, 729-754. [CrossRef]

3. Darbi, M.R.; Karni, E. Free Competition and the Optimal Amount of Fraud. J. Law Econ. 1973, 16, 67-88. [CrossRef]

4. Akerlof, G.A. The Market for "Lemons": Quality Uncertainty and the Market Mechanism. Q. J. Econ. 1970, 84, 488-500. [CrossRef]

5. Anders, S.; Monteiro, D.M.S.; Rouviere, E. Objectiveness in the Market for Third-Party Certification: Does market structure matter? In Proceedings of the 105th EAAE Seminar of International Marketing and International Trade of Quality Food Products, Bologna, Italy, 8-10 March 2007.

6. Berghoef, N.; Dodds, R. Determinants of interest in eco-labelling in the Ontario wine industry. J. Clean. Prod. 2013, 52, 263-271. [CrossRef]

7. The Local. Italian "Organic" Food Fraud Hits German Market, 2011. Available online: http://www.thelocal. de/20111208/39391 (accessed on 8 December 2011).

8. Garcia-Vazquez, E.; Perez, J.; Martinez, J.L.; Pardiñas, A.F.; Lopez, B.; Karaiskou, N.; Casa, M.F.; Machado-Schiaffino, G.; Triantafyllidis, A. High level of mislabeling in Spanish and Greek hake markets suggests the fraudulent introduction of African species. J. Agric. Food Chem. 2011, 59, 475-480. [CrossRef] [PubMed]

9. Dranove, D.; Jin, G.Z. Quality Disclosure and Certification: Theory and Practice. J. Econ. Lit. 2010, 48, 935-963. [CrossRef]

10. Ortega, D.L.; Wang, H.H.; Olynk, N.J.; Wu, L.; Bai, J. Chinese Consumers' Demand for Food Safety Attributes: A Push for Government and Industry Regulations. Am. J. Agric. Econ. 2012, 94, 489-495. [CrossRef]

11. Simon, H.A. A Behavioral Model of Rational Choice. Q. J. Econ. 1955, 69, 99-118. [CrossRef]

12. Rubinstein, A. Modeling Bounded Rationality; MIT Press: Cambridge, MA, USA, 1998. 
13. Loch, C.H.; Wu, Y. Behavioral Operations Management. Found. Trends Technol. Inf. Oper. Manag. 2005, 1, 121-232. [CrossRef]

14. Ariely, D. The End of Rational Economics. Harvard Bus. Rev. 2009, 87, 78-84.

15. Sarafidis, Y. Inter-temporal price discrimination with time inconsistent consumers. In Econometric Society, North American Summer Meetings; No. 479; Econometric Society: Philadelphia, PA, USA, 2004.

16. Chen, Y.; Iyer, G.; Pazgal, A. Limited Memory, Categorization, and Competition. Mark. Sci. 2010, 4, 650-670. [CrossRef]

17. Buehler, B.; Schuett, F. Certification and Minimum Quality Standards under Imperfect Competition, Mimeo. Tilberg University, 2012. Available online: http://www2.dse.unibo.it/dsa/seminari/709/schuett.pdf (accessed on 21 November 2012).

18. Shulman, J.D.; Geng, X. Add-on Pricing by Asymmetric Firms. Manag. Sci. 2013, 59, 899-917. [CrossRef]

19. Lizzeri, A. Information Revelation and Certification Intermediaries. RAND J. Econ. 1999, 30, $214-231$. [CrossRef]

20. Albano, G.; Lizzeri, A. Strategic Certification and Provision of Quality. Int. Econ. Rev. 2001, 42, $267-284$. [CrossRef]

21. Strausz, R. Honest certification and the threat of capture. Int. J. Ind. Org. 2005, 23, 45-62. [CrossRef]

22. Mathis, J.; McAndrews, J.; Rochet, J.C. Rating the raters: Are reputation concerns powerful enough to discipline rating agencies? J. Monet. Econ. 2009, 56, 657-674. [CrossRef]

23. Ibanez, L.; Grolleau, G. Can Ecolabeling Schemes Preserve the Environment? Environ. Resour. Econ. 2008, 40, 233-249. [CrossRef]

24. Villas-Boas, J.M. Dynamic Competition with Customer Recognition. RAND J. Econ. 1999, 30, 604-631. [CrossRef]

25. Shin, J.; Sudhir, K. A Customer Management Dilemma: When Is It Profitable to Reward One's Own Customers? Mark. Sci. 2010, 29, 671-689. [CrossRef]

(C) 2016 by the authors; licensee MDPI, Basel, Switzerland. This article is an open access article distributed under the terms and conditions of the Creative Commons Attribution (CC-BY) license (http://creativecommons.org/licenses/by/4.0/). 